\title{
Physical Activity and Sedentary Behavior Across the Lifespan
}

\author{
Jo Salmon
}

Published online: 7 July 2011

(C) International Society of Behavioral Medicine 2011

When it comes to volume of physical activity, some is better for health than none and more is even better [1], plus participation in a higher intensity physical activity can lead to additional health benefits. There is, however, emerging evidence of beneficial health associations from exchanging sedentary behaviors for light-intensity physical activities (such as standing or light ambulatory activities versus sitting) [2, 3]. The challenge for health professionals is to implement the most effective strategies in the most appropriate settings for promoting physical activity and sedentary behavior control among different groups in the population (i.e., youth, adults, older adults, clinical populations, etc.). Effective interventions targeting physical activity among youth, for example, should take place in settings that will maximize access to this population group, ideally within a fertile context that facilitates behavior change.

The after-school period (sometimes called the "critical window") is one such context about which an evidence base is emerging. The present issue of the International Journal of Behavioral Medicine presents a review of the evidence of effectiveness of strategies to promote physical activity during the after-school period among youth [4]. Atkin and colleagues identified that only three out of the nine studies reviewed were successful in promoting physical activity during the critical window, and programs that were delivered in the school setting were the most

\footnotetext{
J. Salmon $(\triangle)$

Centre for Physical Activity and Nutrition Research,

Deakin University,

221 Burwood Hwy,

Melbourne, VIC 3125, Australia

e-mail: jo.salmon@deakin.edu.au
}

effective. After-school programs delivered in the home or community settings have been infrequently examined, and many of the reported studies are short-term with no evidence of maintenance. While the after-school period offers what appears to be a prime opportunity for promotion of physical activity in youth (e.g., physical activity levels of Australian children peak during this period [5]), more evidence is needed regarding the setting and context in which strategies are most effective.

Two original studies in the present issue report on the effectiveness of strategies to promote physical activity among adults with type 2 diabetes [6] and among older adults [7]. A Belgian study employed a randomized controlled trial to assess the effectiveness of a group therapy general practitioner (GP)-delivered program versus group counseling sessions compared with a usual care control group to promote physical activity among adults with type 2 diabetes [6]. The two intervention groups were also provided with a pedometer. The group counseling sessions were found to be most effective in promoting physical activity $(1,706$ more steps compared with the control group over time) with GPs reporting that they lacked time for more than a 15-min consultation. Evidence suggests that GP referral schemes can be effective in promoting physical activity [8], this includes even brief advice from motivated GPs [9]. However, the additional intervention "dose" received by those in the group counseling arm $(3 \times 90$-min sessions $)$ and the fact that GPs were perhaps not as skilled in delivery as the trained group of counselors may also explain the outcome of this intervention. Interestingly, although both intervention groups received a pedometer, this did not appear to be a sufficient motivational tool to promote physical activity 
among participants in the GP-delivered program, which is in contrast to many previous pedometer studies [10]. Future studies could include an in-depth examination of process evaluation data and mediators and moderators of success of the program.

A key gap in the physical activity promotion literature is in translational studies, where an intervention has been found to be effective under "ideal" conditions, and further research has been performed to assess the "real world" effectiveness of the (often modified) program [11]. The study by Baruth and colleagues [7] employed a pre-post design to examine the effectiveness of a modified version of the Active Living Every Day program on improving physical functioning among older adults. This 20-week group-based lifestyle behavior change program demonstrated significant (small to medium) beneficial effects on functional living tests among older adults, which were not moderated by body mass index or by race/ethnicity. An interesting translational aspect of this program was that over a period of time, the organizations taking part in the delivery requested that the program be shortened to 12 weeks, which did not appear to adversely affect the intervention effectiveness. There is much to be learned about the process of research translation and this paper provides some novel insights.

Not surprisingly, the development of effective interventions to promote health behavior and the ability to detect effects (or lack thereof) is often dependent on an in-depth understanding of participation in these behaviors and an ability to be able to accurately assess them. The remainder of the papers in this issue include: an examination of a measurement model of youth physical activity using a combination of self-, parental proxy-, and peer proxy-report [12]; adults' exercise preferences in sex-segregated or sexintegrated groups and moderation by weight status [13]; associations between women's self-reported time use (employment, home duties, studying, passive, and active leisure) and sitting time on weekdays and weekend days [14]; and an examination of self-efficacy of employed adults for participating in physical activity compared with low or high preferred sedentary behaviors (time displacement) within incremental fixed leisure time scenarios $(20,30,60$, $120 \mathrm{~min}$ of free time) [15].

The studies that involve examination of physical activity and sedentary behaviors clearly demonstrate that these behaviors are unique and not at opposite ends of a behavioral spectrum. In particular, the study by Rhodes and colleagues used behavioral choice theory to test whether perceived self-efficacy to be physically active is sensitive to behavioral preference and perceived time available [15]. The intriguing aspect of that study is that participants reported greater physical activity self-efficacy compared with a highly preferred sedentary behavior (primarily television viewing) if they perceived they had more leisure time available, which suggests that the type of sedentary behavior as well as available time may influence people's choices to be active. There were, however, a number of moderators of time displacement including age, work hours, available free time, education level, and physical activity status. These detailed analyses of physical activity and sedentary preferences $[13,15]$ and how people use their free time [14], as well as the testing of multiple approaches to promoting physical activity [6] and the translation of evidence-based approaches [7] provide rich insights for informing the development of effective tailored approaches which may have more currency with "real world" intervention applications among targeted groups in the population.

Acknowledgments Jo Salmon is supported by a National Heart Foundation of Australia and Sanofi-Aventis Career Development Award.

\section{References}

1. Powell KE, Paluch AE, Blair SN. Physical activity for health: What kind? How much? How intense? On top of what? Ann Rev Public Health. 2011;32:2.1-2.17.

2. Healy GN et al. Breaks in sedentary time: beneficial associations with metabolic risk. Diab Care. 2008;31:661-6.

3. Hamilton MT, Hamilton DG, Zderic TW. Role of low energy expenditure and sitting in obesity, metabolic syndrome, type 2 diabetes, and cardiovascular disease. Diabetes. 2007;56:265567.

4. Atkin AJ, Gorely P, Biddle SJH, Cavill N, Foster C. Interventions to promote physical activity in young people conducted in the hours immediately after school: a systematic review. Int J Behav Med. 2011. doi:10.1007/s12529-010-9111-z.

5. Commonwealth Scientific Industrial Research Organisation (CSIRO). Australian National Children's Nutrition and Physical Activity Survey. Canberra: Australian Government Department of Health and Ageing, Department of Agriculture Fisheries and Forestry. Australian Food and Grocery Council. 2007;2008:1-44.

6. De Greef K, Deforche B, Tudor-Locke C, De Bourdeaudhuij I. Increasing physical activity in Belgian type 2 diabetes patients: a three-arm randomized controlled trial. Int J Behav Med. 2011. doi:10.1007/s12529-010-9124-7.

7. Baruth $\mathrm{M}$ et al. Changes in physical functioning in the Active Living Every Day program of the Active for Life Initiative ${ }^{\circledR}$. Int $J$ Behav Med. 2011. doi:10.1007/s12529-010-9108-7.

8. Sørensen JB, Skovgaard T, Puggard L. Exercise on prescription in general practice: a systematic review. Scand J Primary Health Care. 2006;24:69-74.

9. Armit $\mathrm{CM}$ et al. Randomized trial of three strategies to promote physical activity in general practice. Prev Med. 2009;48:156-63.

10. Bravata DM et al. Using pedometers to increase physical activity and improve health. A systematic review. JAMA. 2007;298:2296304.

11. Salmon J, Jorna M, Hume C, Arundell L, Chahine N, Tienstra M, et al. A translational research intervention to reduce screen behaviours and promote physical activity among children: switch-2-activity. Health Promot Int. 2010. doi:10.1093/heapro/ daq078. 
12. Chaumeton N, Duncan SC, Duncan TE, Strycker LA. A measurement model of youth physical activity using pedometer and self, parent, and peer reports. Int J Behav Med. 2011. doi:10.1007/s12529-010-9118-5.

13. Dunlop WL, Beauchamp MR. En-gendering choice: preferences for exercising in gender-segregated and gender-integrated groups and consideration of overweight status. Int J Behav Med. 2011. doi:10.1007/s12529-010-9125-6.
14. van Uffelen JGZ, Watson MJ, Dobson AJ, Brown WJ. Comparison of self-reported week-day and weekend-day sitting time and weekly time-use: results from the Australian Longitudinal Study on Women's Health. Int J Behav Med. 2011. doi:10.1007/s12529010-9105-x.

15. Rhodes RE, Blanchard CM. Time displacement and confidence to participate in physical activity. Int J Behav Med. 2011. doi:10.1007/s12529-010-9133-6. 